\title{
Moving beyond Type I and Type II neuron types [version 1;
}

\section{peer review: 3 approved]}

\author{
Frances K Skinner(iD) 1,2
}

${ }^{1}$ Toronto Western Research Institute, University Health Network, Toronto, ONT, Canada

${ }^{2}$ Departments of Medicine (Neurology) and Physiology, University of Toronto, Toronto, ONT, Canada

V1 First published: 22 Jan 2013, 2:19

https://doi.org/10.12688/f1000research.2-19.v1

Latest published: 22 Jan 2013, 2:19

https://doi.org/10.12688/f1000research.2-19.v1

\section{Abstract}

In 1948, Hodgkin delineated different classes of axonal firing. This has been mathematically translated allowing insight and understanding to emerge. As such, the terminology of 'Type I' and 'Type II' neurons is commonplace in the Neuroscience literature today. Theoretical insights have helped us realize that, for example, network synchronization depends on whether neurons are Type I or Type II. Mathematical models are precise with analyses (considering Type I/II aspects), but experimentally, the distinction can be less clear. On the other hand, experiments are becoming more sophisticated in terms of distinguishing and manipulating particular cell types but are limited in terms of being able to consider network aspects simultaneously. Although there is much work going on mathematically and experimentally, in my opinion it is becoming common that models are either superficially linked with experiment or not described in enough detail to appreciate the biological context. Overall, we all suffer in terms of impeding our understanding of brain networks and applying our understanding to neurological disease. I suggest that more modelers become familiar with experimental details and that more experimentalists appreciate modeling assumptions. In other words, we need to move beyond our comfort zones.

\section{Open Peer Review}

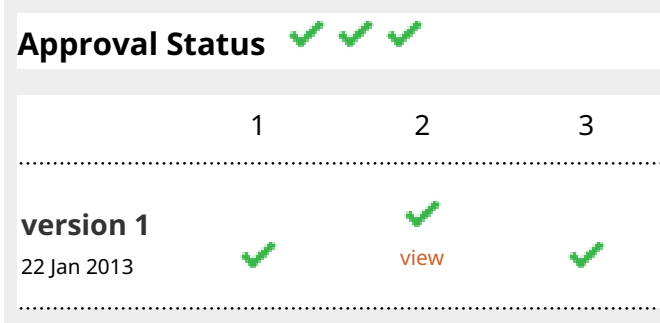

1. Ernest Barreto, George Mason University,

Fairfax, VA, USA

2. Horacio G. Rotstein, New Jersey Institute of Technology (NJIT), Newark, NJ, USA

3. Joel Tabak, Florida State University,

Tallahassee, FL, USA

Any reports and responses or comments on the article can be found at the end of the article.

Corresponding author: Frances K Skinner (frances.skinner@gmail.com)

Competing interests: No competing interests were disclosed.

Grant information: Thanks to Natural Sciences and Engineering Research Council of Canada (NSERC) for continuous support. The funders had no role in study design, data collection and analysis, decision to publish, or preparation of the manuscript.

Copyright: @ 2013 Skinner FK. This is an open access article distributed under the terms of the Creative Commons Attribution License, which permits unrestricted use, distribution, and reproduction in any medium, provided the original work is properly cited. Data associated with the article are available under the terms of the Creative Commons Zero "No rights reserved" data waiver (CCO 1.0 Public domain dedication).

How to cite this article: Skinner FK. Moving beyond Type I and Type II neuron types [version 1; peer review: 3 approved] F1000Research 2013, 2:19 https://doi.org/10.12688/f1000research.2-19.v1

First published: 22 Jan 2013, 2:19 https://doi.org/10.12688/f1000research.2-19.v1 


\section{Introduction}

Current research in my group involves developing, using and analyzing models of neurons and networks in hippocampus. Two aspects relating to the Society for Neuroscience meeting 2012 in New Orleans provided the final push for me to put my thoughts into writing via this opinion piece. First, when being questioned at one of our posters involving fast-spiking inhibitory cell models, we were asked, not for the first time, whether our neuron was Type I or II. Second, a symposium write-up in the Journal of Neuroscience ${ }^{1}$ stated that "...fast-spiking inhibitory cells... have a hard Class 2 threshold...". On the face of it, these are reasonable questions and statements given the theoretical basis of Type I/II neurons ${ }^{2}$. However, on further reflection, I think that such questions and statements may be obscuring the hard challenges and unintentionally developing a divide by focusing on the theory rather than the theory together with the biology.

\section{History and hope}

Hodgkin's (1948) ${ }^{3}$ classification of repetitive firing of axons into three types is common knowledge in the Neuroscience community. Specifically, the first two 'classes' are commonly referred to as Type I and II, where Type I neurons are able to exhibit arbitrarily slow frequencies as injected current levels are reduced, unlike Type II neurons, which cannot. In turn, these Types can be 'translated' to dynamical systems terminology as saddle node on an invariant circle and Andronov-Hopf type bifurcations respectively ${ }^{2}$. Such theoretical interpretations have allowed insight and understanding of the control of axonal firing to be obtained, including the annihilation of firing by appropriately timed inputs ${ }^{4}$. Additional theoretical aspects using Type I/II neurons have been developed. For example, Ermentrout $(1996)^{5}$ has shown that a general property of Type I neurons is that they have phase response curves (PRCs) that are strictly positive. This means that depolarizing stimuli given at any time point of the firing (oscillating) neuron will always lead to an earlier start of the next action potential. This has subsequent implications for the ability of Type I or II neurons to synchronize with excitatory or inhibitory connections. In essence, whether a neuron is Type I or II endows it with different neuro-computational properties. Type I neurons, so called integrators can encode input strength, whereas Type II neurons, so-called resonators, cannot. However, Type II neurons can exhibit subthreshold oscillations, whereas Type I neurons cannot. These and many other interesting aspects are detailed in Izhikevich's book ${ }^{2}$. He envisions a research program in which one is not only concerned with a neuron's details (ion channels etc., as could be explored by experimentalists) but also with its neuro-computational features or what kind of bifurcations it expresses (as could be explored by mathematicians). I agree with this view. Indeed, he states that one of the goals of his book (p.20) is to "...bring these two groups of people closer together". But...

\section{Problem and challenge}

Cellular and synaptic biological details are of course important in the functioning brain, but possibly not all details are critical in all contexts. The expanding field of Connectomics is providing much information about synaptic and architectural details that can be used in computational modeling studies ${ }^{6}$. For cellular aspects, using Type I and II neuron models and their PRC characteristics has been most helpful. For example, Stiefel and Gutkin (2012) ${ }^{7}$ have described how different acetylcholine levels could lead to switching of cortical, pyramidal cells between Type I and II due to modulating biophysical characteristics in cellular models. Based on previous theoretical studies, this would have effects on network synchrony. A switching of PRC characteristics (in terms of Type I/ II) with carbachol has been shown experimentally for Layer $2 / 3$ pyramidal cells. These experimental studies were done in vitro which represents a different synaptic network environment than in vivo ${ }^{8}$. Prescott et al. (2008) $)^{9}$ created an in vivo-like environment in the dish and compared model and experimental work to indicate that CA1 hippocampal pyramidal cells switch from integrators (Type I) to resonators (Type II) when moving from in vitro to in vivo. The modeling studies implicated an M-type potassium current underlying the Type I/II switching.

I would like to highlight two issues that these studies bring forth. First, these cellular-based studies assume that Type I/II differences are important in network synchrony based on prior theoretical studies. It is of note that these differences have now been fully examined in excitatory networks ${ }^{10}$ where network structure, synaptic strength and firing frequencies were examined. The underlying assumption of course is that network synchrony (such as at gamma frequencies) is important in cognitive functioning. Unlike in several invertebrate systems - such as the network controlling the movement of teeth in the stomach of crustaceans ${ }^{11}$ - the function of the neuronal network can be speculative. Second, whether a mathematical model representing a neuron is Type I or II can typically be unambiguously determined using bifurcation analyses. However, whether a neuron in experimental work can be identified as being Type I or II is a bit trickier as the resolution of the injected current as well as the length of time for which the current is injected would affect the resulting frequency-current curve. Tateno et al (2004) $)^{12}$ clearly showed a difference for fast-spiking inhibitory cells (Type II) and regular spiking pyramidal cells (Type I) in rat somatosensory cortex, which underlies the statement of "... hard Class 2" in ${ }^{1}$. Whether one should extrapolate to fast-spiking inhibitory interneurons as being Type II in general is potentially not appropriate as recent studies would seem to indicate that fast-spiking inhibitory interneurons in hippocampus could be Type I, see Figure 6 in ${ }^{13}$. As stated at the beginning of this section, knowing whether a neuron is Type I or II is helpful. However, this may not be the essential aspect when the experimental context and biological specifics are also a focus. For example, Sritharan and Skinner (2012) ${ }^{14}$ used a previously developed biophysical model of a hippocampal interneuron (with Type I-like characteristics) to examine spike reliability. They found that spike reliability at theta frequencies was favoured by an in vivo-like environment that emphasized large inhibitory, but not excitatory, fluctuations. While this did not specifically depend on Type I-like model neurons, the results were more prevalent with Type I-like model neurons. In an earlier study, Tateno and Robinson (2006) ${ }^{15}$ used dynamic clamp to examine Type I (regular spiking) and Type II (fast-spiking) neurons under various conditions involving fluctuating synaptic inputs. They found that while Type I and II aspects still gave rise to differences, this was not always the case. For example, in the context of relative timing of excitatory and inhibitory inputs, as could be important in cortical columnar circuitries, spike reliability and jitter were similar for both types. 
As neuroscientists, we want to understand the workings of our brains and nervous systems, and it is clear that mathematical modeling and theoretical concepts are key to advancing our understanding. However, today, it sometimes feels as if we are trying too hard to fit the biology to the theory rather than using the theory to help us understand the biology/experiment. Indeed, theoretical and modeling studies provide much needed guidance, and consideration of Type I/II neurons has, and will continue to provide such guidance. However - to borrow a statement from the Society for Neuroscience meeting 2012 - we need to 'embrace the messiness' (as stated by Larry Abbott in his Albert and Ellen Grass Lecture "The Collective Wisdom of Neurons"). This interesting talk emphasized having some readout from the biological circuit from which we could come up with reduced descriptions and models to help us understand the system. He pointed out that although we are making progress in determining readouts, progress is limited in linking the reduced circuit models back to the biology. In my opinion, this limited progress may be partly due to insufficient interactions between theoretical, modeling and experimental studies so that the hard but essential questions are less likely to be asked. This is the problem. In the context of what I have presented here, although the dichotomy of Type I and II neurons has been immensely insightful, we need to move beyond this to also be clear about experimental context and biological specifics wherever possible. This is the challenge.

\section{What to do?}

For theoretical analyses, mathematical models need to be in hand. In order for them to be in hand, experimental data has to be consulted. Exactly what data, how much, at what level, and how to access immediately come to the fore. Many different models have been employed in examining Type I and Type II neurons, but if the goal is to get to the heart of the different spike-generating mechanisms exhibited by Type I or II neurons, then clearly one needs to get into spatial aspects and biophysical details. For example, see $^{16}$. However, to understand how and why these detailed differences may be important, a clear context ('readout') is needed. Unfortunately, often this is either not possible and/or very difficult to obtain and/or speculative and unclear. As such, cellular-based network models have been used in different ways ${ }^{17}$. Whether one is focused mainly on readouts or on cellular models, they ultimately need to be linked in some way. How best to go about it is far from clear, but in my opinion (and borrowing a well-known quote), "Resistance is futile". Thus, what to do?

First of all, there should clearly never be any confusion or conflict when comparing modeling or theoretical studies given that model specifics, assumptions and limitations can always be spelled out.
Next, I think that we all need to move beyond our comfort zones more often. That is, modeling studies should make more linkages with experimental studies, suggesting specific and particular next steps so as to help 'get the conversation started'. However, to do this, the practicalities and limitations of experimental studies need to be considered by more modelers (e.g., is there too much variability in the experiment to apply the modeling/theoretical insights? How do model parameters relate to experimental measurements being performed? How are the experiments performed?). Also, experimentalists need to read beyond the model results, questioning and understanding model assumptions and theoretical limitations so that one can assess if and how the model insights might apply and be interpreted in particular experimental and biological situations. There are clearly practical challenges in moving beyond one's comfort zone, but for the greater good (of tackling the immense challenges of understanding brain workings and neurological disease), I think that this needs to be done on a regular basis. While combined efforts require patience, open-mindedness and respect for the realities of different research environments, we should perhaps also try to create more opportunities for "antedisciplinary" science $^{18}$.

\section{In closing}

Recently, I was excited reading an "experimentally inspired theoretical study" ${ }^{\prime 19}$ in which theoretical insights from Rall ${ }^{20}$ were used to shed light on biophysical design specifics. Besides my own interest in the details of the work, I was happy to see this work given what we know about the challenges faced by Rall in his day when he combined theoretical and experimental work. While I have focused on Type I/II issues and examples here, my opinion applies more widely, so that I end this opinion piece with a similar statement used before "Neither ignore the details nor be consumed" by them ${ }^{21}$. Let's move beyond our comfort zones together.

\section{Competing interests}

No competing interests were disclosed.

Grant information

Thanks to Natural Sciences and Engineering Research Council of Canada (NSERC) for continuous support.

The funders had no role in study design, data collection and analysis, decision to publish, or preparation of the manuscript.

Acknowledgements

Thanks to K. Ferguson and V. Sekulic for helpful comments. 
1. Catterall WA, Raman IM, Robinson HP, et al.: The Hodgkin-Huxley Heritage: From Channels to Circuits. J Neurosci. 2012; 32(41): 14064-14073. PubMed Abstract | Publisher Full Text | Free Full Text

2. Izhikevich EM: Dynamical Systems in Neuroscience: The Geometry of Excitability and Bursting. 1st edition. The MIT Press; 2007. Reference Source

3. Hodgkin AL: The local electric changes associated with repetitive action in a non-medullated axon. J Physiol. 1948; 107(2): 165-181. PubMed Abstract | Free Full Text

4. Guttman R, Lewis S, Rinzel J: Control of repetitive firing in squid axon membrane as a model for a neuroneoscillator. J Physiol. 1980; 305: 377-395. PubMed Abstract | Free Full Text

5. Ermentrout B: Type I membranes, phase resetting curves, and synchrony. Neural Comput. 1996; 8(5): 979-1001. PubMed Abstract

6. Leergaard TB, Hilgetag CC, Sporns O: Mapping the connectome: multi-level analysis of brain connectivity. Front Neuroinform. 2012; 6: 14 PubMed Abstract | Publisher Full Text | Free Full Text

7. Stiefel KM, Gutkin BS: Cholinergic Neuromodulation Controls PRC Type in Cortical Pyramidal Neurons. In Phase Response Curves in Neuroscience. edited by Schultheiss NW, Prinz AA, Butera RJ Springer New York; 2012; 6 : 279-305. Publisher Full Text

8. Destexhe A, Rudolph M, Paré D: The high-conductance state of neocortical neurons in vivo. Nat Rev Neurosci. 2003; 4(9): 739-751. PubMed Abstract | Publisher Full Text

9. Prescott SA, Ratté S, De Koninck Y, et al:: Pyramidal neurons switch from integrators in vitro to resonators under in vivo-like conditions. $J$ Neurophysiol. 2008; 100(6): 3030-3042.

PubMed Abstract | Publisher Full Text | Free Full Text

10. Fink CG, Booth V, Zochowski M: Cellularly-Driven Differences in Network Synchronization Propensity Are Differentially Modulated by Firing Frequency. PLoS Comput Biol. 2011; 7(5): e1002062. PubMed Abstract | Publisher Full Text | Free Full Text

11. Harris-Warrick RM, Marder E, Selverston Al, et al.: Dynamic Biological Networks:
The Stomatogastric Nervous System. The MIT Press; 1992. Reference Source

12. Tateno T, Harsch A, Robinson HP: Threshold Firing Frequency-Current Relationships of Neurons in Rat Somatosensory Cortex: Type 1 and Type 2 Dynamics. J Neurophysiol. 2004; 92(4): 2283-2294. PubMed Abstract | Publisher Full Text

13. Ho EC, Strüber M, Bartos M, et al.: Inhibitory Networks of Fast-Spiking Interneurons Generate Slow Population Activities due to Excitatory Fluctuations and Network Multistability. J Neurosci. 2012; 32(29): 9931-9946. PubMed Abstract | Publisher Full Text

14. Sritharan D, Skinner FK: Fluctuating inhibitory inputs promote reliable spiking at theta frequencies in hippocampal interneurons. Front Comput Neurosci. 2012; 6: 30 .

PubMed Abstract | Publisher Full Text | Free Full Text

15. Tateno T, Robinson HP: Rate Coding and Spike-Time Variability in Cortical Neurons With Two Types of Threshold Dynamics. J Neurophysiol. 2006; 95(4): 2650-2663.

PubMed Abstract | Publisher Full Text

16. Higgs $\mathrm{MH}$, Spain $\mathrm{WJ}$ : Kv1 channels control spike threshold dynamics and spike timing in cortical pyramidal neurones. J Physiol. 2011; 589(Pt 21): 5125-5142. PubMed Abstract | Publisher Full Text | Free Full Text

17. Skinner FK: Cellular-based modeling of oscillatory dynamics in brain networks. Curr Opin Neurobiol. 2012; 22(4): 660-669. PubMed Abstract | Publisher Full Text

18. Eddy SR: "Antedisciplinary" science. PLoS Comput Biol. 2005; 1(1): e6. PubMed Abstract | Publisher Full Text | Free Full Text

19. Gidon A, Segev I: Principles Governing the Operation of Synaptic Inhibition in Dendrites. Neuron. 2012; 75(2): 330-341.

PubMed Abstract | Publisher Full Text

20. Rall W, Segev I, Rinzel J, et al.: The Theoretical Foundation of Dendritic Function: Selected Papers of Wilfrid Rall With Commentaries. MIT Press; 1995. Reference Source

21. Skinner FK, Mulloney B: Intersegmental coordination in invertebrates and vertebrates. Curr Opin Neurobiol. 1998; 8(6): 725-732. PubMed Abstract | Publisher Full Text 


\section{Open Peer Review}

\section{Current Peer Review Status:}

\section{Version 1}

Reviewer Report 13 February 2013

https://doi.org/10.5256/f1000research.1159.r766

(C) 2013 Tabak J. This is an open access peer review report distributed under the terms of the Creative Commons Attribution License, which permits unrestricted use, distribution, and reproduction in any medium, provided the original work is properly cited.

\section{Joel Tabak}

Biomedical Research Facility, Florida State University, Tallahassee, FL, USA

Competing Interests: No competing interests were disclosed.

I confirm that I have read this submission and believe that I have an appropriate level of expertise to confirm that it is of an acceptable scientific standard.

Reviewer Report 29 January 2013

https://doi.org/10.5256/f1000research.1159.r739

(C) 2013 Rotstein H. This is an open access peer review report distributed under the terms of the Creative Commons Attribution License, which permits unrestricted use, distribution, and reproduction in any medium, provided the original work is properly cited.

\section{Horacio G. Rotstein}

Department of Mathematical Sciences, New Jersey Institute of Technology (NJIT), Newark, NJ, USA

I think the paper is timely and interesting, here are my comments:

Page 2, column 1: "In turn, these types can be 'translated' to dynamical systems terminology."

To say 'translated' is to imply that dynamical systems tools provide an alternative (and equivalent) description of the dynamics. I don't think this is correct. I think dynamical systems analysis provide a mechanistic explanation of the dynamics in the form of a description of what causes the dynamics. 
Also, the dynamical systems description is correct in 2D. Other dynamics may occur in 3D (e.g., canards that may lead to arbitrarily slow frequencies with an underlying Hopf bifurcation.

Finally, 2D saddle-node bifurcation (away from an invariant circle) can generate type II dynamics, at least theoretically.

Page 2, column 1: "Phase response curves that are always positive."

Although it is probably implicit in the text that follows, it should be noted whether these PRCs correspond to excitation or inhibition.

The classification of type I neurons as integrators and type II neurons as resonators is far from clear to me. In fact, I am not sure that the concept of integrators and resonators is well defined with a definition that has a broad consensus. I might be mistaken, but I think it would be better to leave all that as open questions.

I'm not sure I agree with the statement in "Second,..." (page 2, column 2). I think this is true for 2D systems, but not for higher-dimensional systems.

I strongly agree with the sentence that follows and I think this should be highlighted.

I think that, with appropriate modifications, the sentence at the end of column 2, page 2 "As stated..." should be the first sentence in the paragraph.

Competing Interests: No competing interests were disclosed.

\section{I confirm that I have read this submission and believe that I have an appropriate level of expertise to confirm that it is of an acceptable scientific standard.}

Author Response 21 Feb 2013

Frances Skinner, University Health Network, Toronto, ONT, Canada

All points made by the referee are well-taken. Thank you!

I respond more specifically below - the numbering is for the 6 bullet points of the referee.

1) I completely agree that dynamical systems analyses is about trying to obtain a mechanistic explanation and not just an alternative description. Translated in quotes was used loosely here. 2D was assumed but not explicitly stated as the referee correctly points out.

2) Yes, the assumption is that it corresponds to excitation .

3) The referee has hit upon an essential aspect that I intended to bring forth in this opinion. That is, while mathematical models can be well-defined, biological aspects can only be welldefined when (enough) details and context are also provided. This is what I find is often the 
main challenge in combining experimental work and mathematical modeling.

4) The underlying assumption here again was $2 D$. Thanks for bringing this to the fore.

5) We're on the same page here!

6) While I agree that such modifications could be done, after some thought, I think that it will require quite a bit of readjustment of the flow of the entire 'Problem and Challenge' section. I hope that the referee comments and my response will help readers further hone in to the essential point being made.

That is, while Type I and II aspects can be helpful, they shouldn't become the focal point of our attempts to understand the biological system (as it may not be an important difference in a given biological context). Rather, Type I/II aspects should be considered as a potentially helpful stepping stone.

Competing Interests: None

Reviewer Report 24 January 2013

https://doi.org/10.5256/f1000research.1159.r726

(C) 2013 Barreto E. This is an open access peer review report distributed under the terms of the Creative Commons Attribution License, which permits unrestricted use, distribution, and reproduction in any medium, provided the original work is properly cited.

\section{Ernest Barreto}

School of Physics, Astronomy, and Computational Sciences, George Mason University, Fairfax, VA, USA

Competing Interests: No competing interests were disclosed.

I confirm that I have read this submission and believe that I have an appropriate level of expertise to confirm that it is of an acceptable scientific standard. 
The benefits of publishing with F1000Research:

- Your article is published within days, with no editorial bias

- You can publish traditional articles, null/negative results, case reports, data notes and more

- The peer review process is transparent and collaborative

- Your article is indexed in PubMed after passing peer review

- Dedicated customer support at every stage

For pre-submission enquiries, contact research@f1000.com 